\title{
Structural changes in femoral bone microstructure of female rabbits after intramuscular administration of quercetin
}

\author{
Ramona Babosova' , Hana Duranova', Radoslav Omelka², Veronika Kovacova', Maria Adamkovicova², \\ Birgit Grosskopf ${ }^{3 *}$, Marcela Capcarova ${ }^{4}$ and Monika Martiniakova ${ }^{1}$
}

\begin{abstract}
Background: Quercetin is one of the best known flavonoids being present in a variety of fruits and vegetables. It has cardioprotective, anticarcinogenic, antioxidant, anti-inflammatory and antiapoptotic properties. Some studies suggest that quercetin has protective effects on bone. However, its influence on qualitative and quantitative histological characteristics of compact bone is still unknown. In our study, 12 clinically healthy five-month-old female rabbits were divided into four groups of three animals each. Quercetin was applied intramuscularly in various concentrations; $10 \mu \mathrm{g} / \mathrm{kg}$ body weight (bw) in the E1 group, $100 \mu \mathrm{g} / \mathrm{kg}$ bw in the E2 group, and $1000 \mu \mathrm{g} / \mathrm{kg}$ bw in the E3 group for 90 days, 3 times per week. Three rabbits without exposure to quercetin served as a control (C) group. Differences in femoral bone microstructure among groups were evaluated.

Results: Qualitative histological characteristics of compact bone differed between rabbits from the E1 and E2 groups. Primary vascular longitudinal bone tissue was not found in some areas near the endosteal surface due to increased endocortical bone resorption. In addition, periosteal border of rabbits from the E1 group was composed of a thicker layer of primary vascular longitudinal bone tissue than in the other groups. In all groups of rabbits administered quercetin, a lower density of secondary osteons was observed. Histomorphometrical evaluations showed significantly decreased sizes of the primary osteons' vascular canals in individuals from the E1 and E2 groups. Secondary osteons were significantly smaller in rabbits from the E1, E2, E3 groups when compared to the C group. Cortical bone thickness was significantly increased in females from the E1 and E2 groups.
\end{abstract}

Conclusions: The results indicate that quercetin has not only a positive dose-response on qualitative and quantitative histological characteristics of the compact bone of female rabbits as it would be expected.

Keywords: Bone microstructure, Histomorphometry, Quercetin, Rabbit, Intramuscular administration

\section{Background}

Flavonoids belong to the group of polyphenolic secondary herbal substances that have beneficial effects on human health [1]. Quercetin (2-(3,4-dihydroxyphenyl)-3,5,7-trihydroxy-4H-1-benzopyran-4-one; 3,3,4,5,7-pentahydroxyflavone) is one of the best characterized flavonoids present in fruits and vegetables [2]. It has cardioprotective [3], anticarcinogenic [4], antioxidant [5], anti-inflammatory [6]

\footnotetext{
*Correspondence: birgit.grosskopf@biologie.uni-goettingen.de

${ }^{3}$ Institute of Zoology and Anthropology, Georg-August University,

37073 Göttingen, Germany

Full list of author information is available at the end of the article
}

and antiapoptotic properties [7]. It also protects against reactive oxygen species (ROS) and reactive nitrogen species (RNS) $[8,9]$. Some studies $[10,11]$ suggest that quercetin also has protective effects on bone as it inhibits bone loss by affecting osteoclastogenesis. Horcajada-Molteni et al. [12] and Tsuji et al. [13] state that quercetin and its dietary analogue rutin inhibit osteopenia in ovariectomized rats. On the other hand, quercetin stimulates differentiation of osteoblasts and MG-63 osteoblast-like cells in rats [14]. Besides its beneficial health effects, potentially toxic actions of quercetin related to mutagenicity, prooxidant activity, mitochondrial toxicity, and inhibition of key 
enzymes involve in hormone metabolism have been demonstrated $[15,16]$. However, the impact of quercetin on qualitative and quantitative histological characteristics of the compact bone is still unknown. Therefore, the aim of this study was to investigate femoral bone microstructure of adult female rabbits after intramuscular application of quercetin.

\section{Methods}

\section{Animals}

The study was conducted on 12 clinically healthy adult female rabbits of meat line M91, maternal albinotic line (crossbreed New Zealand White, Buskat rabbit, French Silver) and paternal acromalictic line (crossbreed Nitra's rabbit, Californian rabbit, Big Light Silver) of approximately 5 months of age, with a body weight (bw) of $4.00 \pm 0.5 \mathrm{~kg}$. Animals were obtained from an experimental farm of the Animal Production Research Centre in Nitra (Slovak Republic) and were housed in individual flat-deck wire cages under a constant photoperiod of $12 \mathrm{~h}$ of daylight, temperature $20-24{ }^{\circ} \mathrm{C}$ and humidity $55 \pm 10 \%$, with an access to food (feed mixture) and drinking water ad libitum. Adult female rabbits were randomly divided into four groups of three animals each: E1, E2, E3 and C. The rabbits from the E1, E2 and E3 groups were intramuscularly injected with quercetin (SigmaAldrich, Germany) at doses of 10, 100 and $1000 \mu \mathrm{g} / \mathrm{kg}$ bw, respectively for 90 days, 3 times per week. The doses of quercetin (reflecting the natural exposure of animals to quercetin in rabbit feed) were chosen based on literature data [17-19]. Rabbits from the $C$ group (controls) were injected by a saline solution at the same time for 90 days. In general, the rabbits were kept for other investigations (e.g. histological and biochemical analyses) at the Animal Production Research Centre in Nitra. The present study was performed as an additional investigation focused on compact bone microstructure.

\section{Procedures}

At the end of experimental period (i.e. after 90 days), all the rabbits were killed and their femurs were used for analyses. For histological evaluation, the right femurs were sectioned at the diaphyseal midshaft and the segments were fixed in HistoChoice fixative (Amresco, USA). The segments were then dehydrated in increasing grades (40-100 \%) of ethanol and embedded in Biodur epoxy resin (Günter von Hagens, Heidelberg, Germany) as previously described [20]. Transverse sections (70$80 \mu \mathrm{m}$ ) were prepared with a sawing microtome (Leitz 1600, Leica, Wetzlar, Germany) and fixed onto glass slides by Eukitt (Merck, Darmstadt, Germany) [21]. The qualitative histological characteristics of the compact bone were determined according to the internationally accepted classification systems of Enlow and Brown [22] and de Ricqlés et al. [23], who classify bone tissue into three main categories: primary vascular tissue, nonvascular tissue and Haversian bone tissue. Various patterns of vascularization occur in primary vascular bone tissue: longitudinal, radial, reticular, plexiform, laminar, lepidosteoid, acellular, fibriform and protohaversian. Three subcategories in Haversian bone tissue are known: irregular, endosteal and dense. The quantitative (histomorphometrical) variables were assessed using the software Motic Images Plus 2.0 ML (Motic China Group Co., Ltd.). We measured area, perimeter, minimum and maximum diameters of primary osteons' vascular canals, Haversian canals, and secondary osteons in the four cross-sectional quadrants (i.e. anterior, posterior, medial and lateral) to minimize inter-animal differences. The diaphyseal cortical bone thickness was also measured by Motic Images Plus 2.0 ML software. Twenty random areas were selected and average thickness was calculated for each femur.

\section{Statistics}

Statistical analysis was performed using SPSS 8.0 software. All data were expressed as mean \pm standard deviation (SD). The unpaired Games-Howell's test was used for establishing statistical significance between all groups.

\section{Results}

\section{Qualitative histological analysis}

The periosteal and endosteal surfaces of femurs in rabbits from the $\mathrm{C}$ group were formed by primary vascular longitudinal bone tissue. This tissue included vascular canals, which ran in a direction essentially parallel to the long axis of the bone. Near endosteal surfaces, primary vascular radial bone tissue (formed by branching or nonbranching vascular canals radiating from the marrow cavity) and/or Haversian bone tissues were also found. Haversian bone tissue was characterized by the presence of isolated and scattered secondary osteons (irregular Haversian bone tissue) or by a large density of the osteons (dense Haversian bone tissue). The middle part of the substantia compacta was formed by a layer of irregular and/or dense Haversian bone tissues (Fig. 1a).

Rabbits exposed to quercetin displayed differences in compact bone microstructure compared to the $C$ group. In rabbits from the E1 (Fig. 1b) and E2 (Fig. 1c) groups, primary vascular longitudinal bone tissue was not observed in some areas (in anterior and posterior views) near endosteal surfaces. These areas were created by primary vascular radial and/or Haversian bone tissues. The middle part of substantia compacta was formed not only by Haversian bone tissue but also by primary vascular longitudinal bone tissue. In rabbits from the E1 group, the 


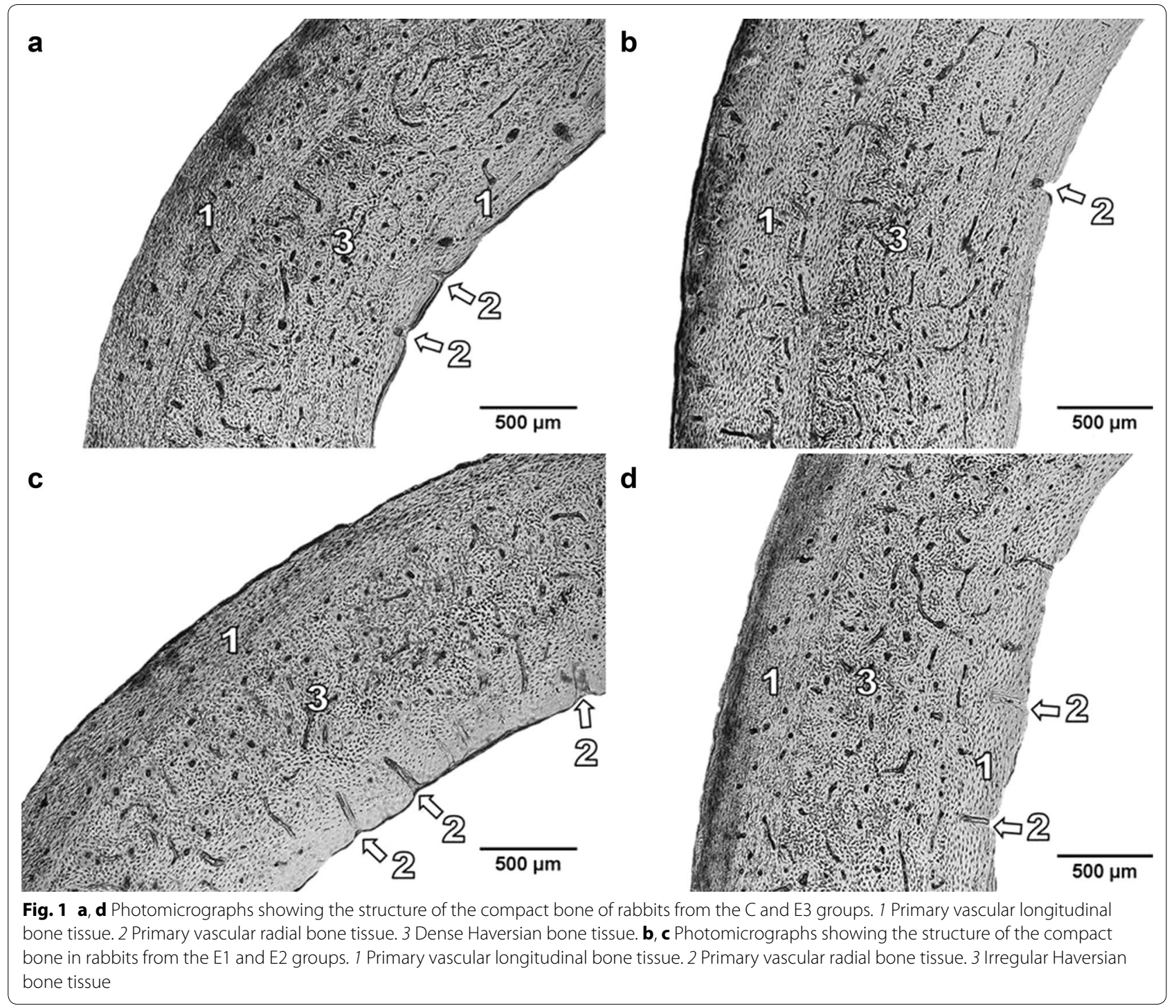

periosteal border consisted of a thicker layer of primary vascular longitudinal bone tissue when compared to the other groups. The animals from the E3 (Fig. 1d) group had a compact bone microstructure similar to rabbits from the $\mathrm{C}$ group although the number of secondary osteons was lower as found in rabbits from the E1 and E2 groups.

\section{Quantitative histological analysis}

In total, 480 vascular canals of primary osteons, 480 Haversian canals and 480 secondary osteons were measured. The results are summarized in Table 1 . All variables (area, perimeter, maximum and minimum diameters) of the primary osteons' vascular canals were significantly decreased in groups E2 and E3 when compared to the C group. Significant differences were also found between E1 and E2, and E1 and E3 groups (except for minimum diameter). Haversian canals' values did not differ significantly between groups. On the other hand, secondary osteon values were significantly lower in rabbits from the E1, E2 and E3 groups compared to the C group. Significant differences were also demonstrated between the E1 and E2 groups.

Cortical bone thickness of rabbits from the E1 and E2 groups was significantly increased compared to the $C$ group. In addition, statistically significant differences were also identified between the groups E1 and E2, and the groups E1 and E3 (Table 2).

\section{Discussion}

The results of qualitative histological analysis are in accordance to those of others [24-26]. Primary vascular longitudinal, primary vascular radial, irregular 
Table 1 Data of the primary osteons' vascular canals, Haversian canals and secondary osteons in adult rabbits from the $E 1, E 2$, E3 and C groups

\begin{tabular}{|c|c|c|c|c|c|c|c|}
\hline & Rab & s group & $N$ & $\begin{array}{l}\text { Area } \\
\left(\mu \mathrm{m}^{2}\right)\end{array}$ & $\begin{array}{l}\text { Perimeter } \\
(\mu \mathrm{m})\end{array}$ & $\begin{array}{l}\text { Max. diameter } \\
(\mu \mathrm{m})\end{array}$ & $\begin{array}{l}\text { Min. diameter } \\
(\mu \mathrm{m})\end{array}$ \\
\hline \multirow[t]{5}{*}{ Vascular canals of primary osteons } & E1 & $(1)$ & 120 & $399.27 \pm 63.02$ & $71.83 \pm 5.84$ & $12.57 \pm 1.39$ & $10.15 \pm 1.02$ \\
\hline & E2 & (2) & 120 & $358.42 \pm 52.11$ & $67.82 \pm 4.88$ & $11.77 \pm 1.02$ & $9.73 \pm 1.00$ \\
\hline & E3 & (3) & 120 & $359.38 \pm 62.33$ & $67.90 \pm 5.66$ & $11.75 \pm 1.18$ & $9.77 \pm 1.14$ \\
\hline & C & (4) & 120 & $408.30 \pm 79.95$ & $72.22 \pm 7.21$ & $12.43 \pm 1.45$ & $10.45 \pm 1.34$ \\
\hline & \multicolumn{3}{|c|}{ Games-Howell's test } & $\begin{array}{l}1: 2^{* *} ; 1: 3^{* *} ; \\
2: 4^{* *} ; 3: 4^{* *^{\prime}}\end{array}$ & $\begin{array}{l}1: 2^{* *} ; 1: 3^{* *} ; \\
2: 4^{* *} ; 3: 4^{* *^{\prime}}\end{array}$ & $\begin{array}{l}1: 2^{* *} ; 1: 3^{* *} ; \\
2: 4^{* *} ; 3: 4^{* *^{\prime}}\end{array}$ & $1: 2^{*} ; 1: 3^{* *} ; 2: 4^{* *}$ \\
\hline \multirow[t]{5}{*}{ Haversian canals } & E1 & $(1)$ & 120 & $329.56 \pm 57.64$ & $65.15 \pm 5.51$ & $11.33 \pm 1.16$ & $9.30 \pm 1.17$ \\
\hline & E2 & (2) & 120 & $317.14 \pm 54.53$ & $63.84 \pm 5.67$ & $11.08 \pm 1.27$ & $9.15 \pm 1.04$ \\
\hline & E3 & (3) & 120 & $318.62 \pm 56.46$ & $64.02 \pm 5.63$ & $11.18 \pm 1.16$ & $9.10 \pm 1.07$ \\
\hline & C & (4) & 120 & $334.86 \pm 69.49$ & $65.47 \pm 6.67$ & $11.37 \pm 1.35$ & $9.38 \pm 1.18$ \\
\hline & \multicolumn{3}{|c|}{ Games-Howell's test } & NS & NS & NS & NS \\
\hline \multirow[t]{5}{*}{ Secondary osteons } & E1 & (1) & 120 & $5976.51 \pm 2236.50$ & $276.00 \pm 51.00$ & $48.79 \pm 9.85$ & $38.04 \pm 8.15$ \\
\hline & E2 & (2) & 120 & $4945.24 \pm 1691.32$ & $252.24 \pm 44.01$ & $44.93 \pm 8.60$ & $34.31 \pm 7.17$ \\
\hline & E3 & (3) & 120 & $5355.22 \pm 2046.25$ & $262.10 \pm 48.34$ & $46.37 \pm 9.67$ & $35.97 \pm 7.77$ \\
\hline & C & (4) & 120 & $6982.93 \pm 2773.93$ & $299.10 \pm 55.97$ & $53.13 \pm 10.65$ & $40.80 \pm 9.44$ \\
\hline & \multicolumn{3}{|c|}{ Games-Howell's test } & $\begin{array}{l}1: 2^{* *} ; 1: 4^{*} ; \\
2: 4^{* * *} ; 3: 4^{* *}\end{array}$ & $\begin{array}{l}1: 2^{* *} ; 1: 4^{*} ; \\
2: 4^{* *} ; 3: 4^{* *}\end{array}$ & $\begin{array}{l}1: 2^{* *} ; 1: 4^{*} ; \\
2: 4^{* *} ; 3: 4^{* *}\end{array}$ & $1: 2^{* *} ; 2: 4^{* *} ; 3: 4^{* *}$ \\
\hline
\end{tabular}

$N$ number of measured structures; NS non-significant differences

$P<0.05\left({ }^{*}\right) ; P<0.01(* *)$

Table 2 Cortical bone thickness in adult rabbits from the $E 1, E 2, E 3$ and $C$ groups

\begin{tabular}{llll}
\hline Rabbits group & $\mathbf{N}$ & Cortical bone thickness $(\boldsymbol{\mu m})$ \\
\hline E1 & $(1)$ & 120 & $1224.78 \pm 160.09$ \\
E2 & $(2)$ & 120 & $1104.79 \pm 127.29$ \\
E3 & $(3)$ & 120 & $1059.01 \pm 151.78$ \\
C & $(4)$ & 120 & $1055.53 \pm 112.34$ \\
Games-Howell's test & & $1: 2^{* *} ; 1: 3^{* *} ;$ \\
\end{tabular}

$N$ number of measurements

$P<0.05$ (*); $P<0.01$ (**) $^{*}$

Haversian and/or dense Haversian bone tissues were found in all groups of rabbits. However, exposure to quercetin at levels of 10,100 , and $1000 \mu \mathrm{g} / \mathrm{kg}$ bw three times per week through 90 days leads to changes such as increased bone resorption, lower number of secondary osteons in the compact bone microstructure. These lesions were the most significant in rabbits exposed to the lowest dose of quercetin (10 $\mu \mathrm{g} / \mathrm{kg}$ bw; E1 group), although they were also present in the E2 group given a dose of $100 \mu \mathrm{g} / \mathrm{kg}$ bw. The absence of primary vascular longitudinal bone tissue in some areas near the endosteal border and a lower density of secondary osteons in the middle part of the substantia compacta in these animals influences accelerated bone resorption at the endosteal surface.
Despite an increasing knowledge of quercetin's beneficial activities as high potential free radical scavenger in vitro, it may also have prooxidant effects under certain conditions $[27,28]$. This prooxidant activity can contribute to the generation of ROS $[29,30]$ which have been shown to stimulate osteoclastic bone resorption [31].

According to Ahlborg et al. [32], excessive bone loss from the endocortical surface induces a mechanical stress on bone tissue, resulting in stimulation of periosteal bone apposition. Deposition of bone tissue onto the periosteal surface is considered to be an adaptive bone response to maintain resistance to bone loss and fractures. In our study, the predominance of periosteal bone apposition over endocortical bone resorption was associated with the thickest layer of primary vascular longitudinal bone tissue (E1 group) and increased thickness of cortical bone in rabbits from the E1 and E2 groups [33, 34]. The lower density of secondary osteons in the middle part of substantia compacta in rabbits from the E1, E2 and E3 groups could lead to weakness of biomechanical properties of their bones due to increased formation of microcracks [35].

The results also revealed significantly decreased sizes of the primary osteons' vascular canals in rabbits from the E2 and E3 groups. Primary osteons' vascular canals contain blood vessels which provide nutrition for the bone [36]. Pries et al. [37] showed that blood vessels can adapt its structure (vascular remodeling) in response 
to continuous functional changes. The results of several in vitro studies [38-41] documented the suppressive effect of quercetin on the expression of enzyme nitric oxide synthase (eNOS), which catalyzes a release of nitric oxide (NO), and endothelial cell proliferation. $\mathrm{NO}$ acts as a potential vasodilator and decreased production leads to vasoconstriction of blood vessels [42]. Therefore, the reduced size of primary osteons' vascular canals may be associated with structural changes of blood vessels present in primary osteons due to a negative effect of higher doses of quercetin on the eNOS expression. In addition, vascular endothelial growth factor (VEGF) is considered to play a central role in angiogenesis under pathological conditions [43, 44]. Several studies [45-47] have demonstrated an inhibitory effect of quercetin on the expression of VEGF. Furthermore, the inhibitory effect of quercetin on proliferation, migration and differentiation of endothelial cells during angiogenesis was observed $[48,49]$. For this reason, quercetin-induced changes during angiogenesis could contribute to the smaller primary osteons' vascular canals in rabbits from the E2 and E3 groups. Interestingly, the size of the vascular canals of primary osteons did not change in rabbits from the E1 group. This indicates a dose-dependent effect of quercetin on their size. On the other hand, significantly decreased sizes of the secondary osteons were observed in all groups exposed to quercetin. We assume that evident alterations in the size of secondary osteons in these animals could be related to the destruction of collagen fibers present in the secondary osteons [50]. Kang et al. [51] found that quercetin $(6.25-50 \mu \mathrm{mol} / \mathrm{l})$ inhibited collagen synthesis on keloid-derived fibroblasts in vitro. The negative effect of various concentrations of quercetin (20,40, and $80 \mu \mathrm{mol} / \mathrm{l}$ ) on collagen reduction (more than $50 \%$ in case of the highest dose) in human fibroblasts was also confirmed by Stipcevic et al. [52].

\section{Conclusions}

The study demonstrates that prolonged intramuscular application of quercetin has a significant effect on both qualitative and quantitative histological characteristics of the compact bone in adult female rabbits at doses of 10,100 , and $1000 \mu \mathrm{g} / \mathrm{kg} \mathrm{bw}$. A positive dose-response of quercetin has been identified for the sizes of primary osteons' vascular canals and secondary osteons. On the contrary, quercetin had a negative dose-response on qualitative histological characteristics of the compact bone and cortical bone thickness. Our study provides initial information related to quercetin's impact on femoral bone microstructure in rabbits. These findings may be useful for future insights into bone microstructural changes after the application of various nutrients.

\section{Authors' contributions}

RB was responsible for quantitative histological analysis of bones and writing the article. HD was responsible for qualitative histological analysis of bones. $\mathrm{RO}$ was responsible for the statistical analysis. VK was responsible for cortical bone thickness analysis. MA was responsible for photodocumentation of histological sections. BG was responsible for preparation of histological sections and corresponds with co-authors. MC was responsible for animal care and sampling of femora. MM conceived and designed the research and helped with writing an article. All authors read and approved the final manuscript.

\section{Author details \\ ${ }^{1}$ Department of Zoology and Anthropology, Constantine the Philosopher University, 94974 Nitra, Slovakia. ${ }^{2}$ Department of Botany and Genetics, Constantine the Philosopher University, 94974 Nitra, Slovakia. ${ }^{3}$ Institute of Zoology and Anthropology, Georg-August University, 37073 Göttingen, Germany. ${ }^{4}$ Department of Animal Physiology, Slovak University of Agriculture, 94976 Nitra, Slovakia.}

\section{Competing interests}

All authors declare that they have no competing interests.

\section{Ethics approval and consent to participate}

Institutional and national guidelines for the care and use of animals were followed and all experimental procedures were approved by the State Veterinary and Food Institute of Slovak Republic, no. 3398/11-221/3.

\section{Funding}

This study was supported by the Grants VEGA 1/0653/16 and KEGA 031 UKF-4/2016. This work was supported by Research Centre AgroBioTech built in accordance with the project Building Research Centre "AgroBioTech" ITMS 26220220180

Received: 13 April 2016 Accepted: 17 June 2016

Published online: 29 June 2016

\section{References}

1. Middleton E Jr, Kandaswami C, Theoharides TC. The effects of plant flavonoids on mammalian cells: implications for inflammation, heart disease, and cancer. Pharmacol Rev. 2000;52:673-751.

2. Chen C, Zhou J, Ji C. Quercetin: a potential drug to reverse multidrug resistance. Life Sci. 2010;87:333-8.

3. Nordeen SK, Bona BJ, Jones DN, Lambert JR, Jackson TA. Endocrine disrupting activities of the flavonoid nutraceuticals luteolin and quercetin. Horm Cancer. 2013;4:293-300.

4. Zhang F, Cui Y, Cao P. Effect of quercetin on proliferation and apoptosis of human nasopharyngeal carcinoma HEN1 cells. J Huazhong Univ Sci Technol Med Sci. 2008;28:369-72.

5. Wein S, Behm N, Petersen RK, Kristiansen K, Wolffram S. Quercetin enhances adiponectin secretion by a PPAR-gamma independent mechanism. Eur J Pharm Sci. 2010;41:16-22.

6. Wein S, Schrader E, Rimbach G, Wolffram S. Oral quercetin supplementation lowers plasma sICAM-1 concentrations in female $\mathrm{db} / \mathrm{db}$ mice. Pharmacol Pharm. 2013;4:77-83.

7. Csokay B, Prajda N, Weber G, Olah E. Molecular mechanisms in the antiproliferative action of quercetin. Life Sci. 1997;60:2157-63.

8. Nickel T, Hanssen H, Sisic Z, Pfeiler S, Summo C, Schmauss D, Hoster E, Weis M. Immunoregulatory effects of the flavonol quercetin in vitro and in vivo. Eur J Nutr. 2011;50:163-72.

9. Dehghan G, Khoshkam Z. Tin (II) - quercetin complex: synthesis, spectral characterization and antioxidant activity. Food Chem. 2012;131:422-6.

10. Boots AW, Li H, Schins RP, Duffin R, Heemskerk JW, Bast A, Haenen GR. The quercetin paradox. Toxicol Appl Pharmacol. 2007;222:89-96.

11. Sharan K, Mishra JS, Swarnkar G, Siddiqui JA, Khan K, Kumari R, Rawat P, Maurya R, Sanyal S, Chattopadhyay N. A novel quercetin analogue from a medicinal plant promotes peak bone mass achievement and bone healing after injury and exerts an anabolic effect on osteoporotic bone: the role of aryl hydrocarbon receptor as a mediator of osteogenic action. J Bone Miner Res. 2011;26:2096-111. 
12. Horcajada-Molteni MN, Crespy V, Coxam V, Davicco MJ, Remesy C, Barlet JP. Rutin inhibits ovariectomy-induced osteopenia in rats. J Bone Miner Res. 2000;15:2251-8.

13. Tsuji M, Yamamoto H, Sato T, Mizuha Y, Kawai Y, Taketani Y, Kato S, Terao J, Inakuma T, Takeda E. Dietary quercetin inhibits bone loss without effect on the uterus in ovariectomized mice. J Bone Miner Metab. 2009;27:673-81.

14. Prouillet C, Maziereb JC, Maziereb C. Stimultatory effect of naturally occurring flavonols quercetin and kaempferol on alkaline phosphatase activity in MG-63 human osteoblasts through EKR and estrogen receptor pathway. Biochem Pharmacol. 2004;67:1307-13.

15. Okamoto T. Safety of quercetin for clinical application. Int J Mol Med. 2005;16:275-8.

16. Zhang Q, Zhao XH, Wang ZJ. Cytotoxicity of flavones and flavonols to a human esophageal squamous cell carcinoma cell line (KYSE-510) by induction of G2/M arrest and apoptosis. Toxicol In Vitro. 2009;23:797-807.

17. Choi JS, Li X. Enhanced diltiazem bioavailability after oral administration of diltiazem with quercetin to rabbits. Int J Pharm. 2005;297:1-8.

18. Knab AM, Shanely RA, Jin F, Austin MD, Sha W, Nieman DC. Quercetin with vitamin $C$ and niacin does not affect body mass or composition. Appl Physiol Nutr Metab. 2011;36:331-8.

19. Lesniak AW, Kolesarova A, Medvedova M, Maruniakova N, Capcarova M, Kalafova A, Hrabia A, Sirotkin AV. Proliferation and apoptosis in the rabbit ovary after administration of T-2 toxin and quercetin. J Anim Feed Sci. 2013;22:264-71.

20. Martiniakova M, Omelka R, Grosskopf B, Sirotkin AV, Chrenek P. Sex-related variation in compact bone microstructure of the femoral diaphysis in juvenile rabbits. Acta Vet Scand. 2008;50:15.

21. Martiniakova M, Omelka R, Jancova A, Stawarz R, Formicki G. Heavy metal content in the femora of yellow-necked mouse (Apodemus flavicollis) and wood mouse (Apodemus sylvaticus) from different types of polluted environment in Slovakia. Environ Monit Assess. 2010;171:651-60.

22. Enlow DH, Brown SO. A comparative histological study of fossil and recent bone tissues. Part I. Texas J Sci. 1956;8:405-12.

23. de Ricqles AJ, Meunier FJ, Castanet J, Francillon-Vieillot H. Comparative microstructure of bone. In: Hall BK, editor. Bone 3, bone matrix and bone specific products. Boca Raton: CRC Press; 1991. p. 1-78.

24. Enlow DH, Brown SO. A comparative histological study of fossil and recent bone tissues. Part III. Texas J Sci. 1958;10:187-230.

25. Martiniaková M, Vondráková M, Fabiš M. Investigation of the microscopic structure of rabbit compact bone tissue. Scripta Medica (Brno). 2003:76:215-20

26. Martiniakova M, Omelka R, Chrenek P, Vondrakova M, Bauerova M. Agerelated changes in histological structure of the femur in juvenile and adult rabbits: a pilot study. Bull Vet Inst Pulawy. 2005;49:227-30.

27. Wattel A, Kamel S, Mentaverri R, Lorget F, Prouillet C, Petit JP, Ferdelonne P, Brazier M. Potent inhibitory effect of naturally occurring flavonoids quercetin and kaempferol on in vitro osteoclastic bone resorption. Biochem Pharmacol. 2003;65:35-42.

28. Woo JT, Nakagawa H, Notoya M. Quercetin suppresses bone resorption by inhibiting the differentiation and activation of osteoclasts. Biol Pharm Bull. 2004;4:504-9.

29. Metodiewa D, Jaiswal AK, Cenas N, Dickancaite E, Sequra-Aquilar J. Quercetin may act a cytotoxic prooxidant after its metabolic activation to semiquinone and quinoidal product. Free Radic Biol Med. 1999;26:107-16

30. Harwood M, Danielewska-Nikiel B, Borzelleca JF, Flamm GW, Williams GM, Lines TC. A critical review of the data related to the safety of quercetin and lack of evidence of in vivo toxicity, including lack of genotoxic/carcinogenic properties. Food Chem Toxicol. 2007;45:2179-205.
31. Garret IR, Boyce BF, Oreffo ROC, Bonewald L, Poser J, Mundy GR. Oxygenderived free radicals stimulate osteoclastic bone resorption in rodent bone in vitro and in vivo. J Clin Invest. 1990;85:632-9.

32. Ahlborg HG, Johnell O, Turner CH, Rannevik G, Karlsson MK. Bone loss and bone size after menopause. N Engl J Med. 2003;349:327-34.

33. Seeman E. The periosteum - a surface for all seasons. Osteoporos Int. 2007:18:123-8.

34. Seeman E. Bone quality: the material and structural basis of bone strength. J Bone Miner Metab. 2008;26:1-8.

35. O'Brien FJ, Taylor D, Lee TC. The effect of bone microstructure on the initiation and growth of microcracks. J Orthop Res. 2005;23:475-80.

36. Greenlee DM, Dunnell RC. Identification of fragmentary bone from the Pacific. J Archaeol Sci. 2010;37:957-70.

37. Pries AR, Reglin B, Secomb TW. Remodeling of blood vessels: responses of diameter and wall thickness to hemodynamic and metabolic stimuli. Hypertension. 2005;46:725-31.

38. Leikert JF, Rathel TR, Wohlfart P, Cheynier V, Vollmar AM, Dirsch VM. Red wine polyphenols enhance endothelial nitric oxide synthase expression and subsequent nitric oxide release from endothelial cells. Circulation. 2002;106:1614-7.

39. Huisman A, Van De Wiel A, Rabelink TJ, Van Faassen EE. Wine polyphenols and ethanol do not significantly scavenge superoxide nor affect endothelial nitric oxide production. J Nutr Biochem. 2004;15:426-32.

40. Wallerath T, Li H, Godtel-Ambrust U, Schwarz PM, Forstermann U. A blend of polyphenolic compounds explains the stimulatory effect of red wine on human endothelial NO synthase. Nitric Oxide. 2005;12:97-104.

41. Jackson SJ, Venema RC. Quercetin inhibits eNOS, microtubule polymerization, and mitotic progression in bovine aortic endothelial cells. J Nutr. 2006;136:1178-84.

42. Martynowicz H, Skoczyńska A, Wojakowska A, Turczyn B. Serum vasoactive agents in rats poisoned with cadmium. Int J Occup Med Environ Health. 2004;17:479-85.

43. Adair TH, Montani JP. Angiogenesis. San Rafael: Morgan \& Claypool Life Sciences; 2010.

44. Kim J, Lim W, Ko Y, Kwon H, Kim S, Kim O, Park G, Choi H, Kim O. The effect of cadmium on VEGF-mediated angiogenesis in HUVECs. J Appl Toxicol. 2012:32:342-9

45. Zhong L, Chen FY, Wang HR, Ten Y, Wang C, Ouyang RR. Effects of quercetin on morphology and VEGF secretion of leukemia cells NB4 in vitro. Zhonghua Zhong Liu Za Zhi. 2006;28:25-7.

46. Hung $H$. Dietary quercetin inhibits proliferation of lung carcinoma cells. Forum Nutr. 2007:60:146-57.

47. Santini SE, Basini G, Bussolati S, Graselli F. The phytoestrogen quercetin impairs steroidogenesis and angiogenesis in swine granulosa cells in vitro. J Biomed Biotechnol. 2009;2009:1-8.

48. Igura K, Ohta T, Kuroda Y, Kaji K. Resveratrol and quercetin inhibit angiogenesis in vitro. Cancer Lett. 2001;171:11-6.

49. Songo I, Vannini N, Lorusso G, Cammarota R, Noonan DM, Generoso L, Sporn MB, Albini A. Anti-angiogenic activity of a novel class of chemopreventive compounds: oleanic acid terpenoids. Recent Results Cancer Res. 2009;181:209-12.

50. Dylevsky I. Obecná kineziologie (in Czech). Praha: Grada Publishing; 2007.

51. Kang LP, Qi LH, Zhang JP, Shi N, Zhang M, Wu TM, Chen J. Effect of genistein and quercetin on proliferation, collagen synthesis, and type I procollagen mRNA levels of rat hepatic stellate cells. Acta Pharmacol Sin. 2001;22:793-6.

52. Stipcevic T, Piljac J, Vanden Berghe D. Effect of different flavonoids on collagen synthesis in human fibroblasts. Plant Foods Hum Nutr. 2006;61:29-34 